\title{
GREATER OCCIPITAL NERVE BLOCK CRYOLESION IN MIGRAINE HEADACHE TREATMENT
}

SURGERY OF CHRONIC PAIN TREATMENT Jagiellońska 67a/U1, Szczecin 70-382 Poland

MAGDALENA PASZKOWSKA,magdalena2@autograf.pl

specialist of anaesthesiology and intensive care, specialist of paliative medicine

\section{CASE REPORT}

BACKGROUND: A 30-year-old female patient, suffering from migraine headaches since she turned 17.Migraine headaches intensified after the first child birth (2012). She was neurologically consulted. MR scan of the head was performed in 2015 , the result- normal. Paroxysmal migraine with aura was diagnosed. At least 10 days per month with severe, pulsing, throbbing pain, with nausea and vomits, headaches kept the patient awake during nights, headaches occured alternately on the right or left side. NRS 10. Headaches were provoked and intensified by: noise, physical effort, some scents, smoking. Pharmacotherapy: paracetamol, ibuprofen, sumatryptan, tolfenamic acid, dihydroergotamin, solpadeina( paracetamol+koffein+codein)gives short-lasting effect. In medical history: occasional smoker, contraception ( IUD ). Treated at a chronic pain treatment office since a year. Three times therapeutic greater occipital nerve block with local anaesthestics ( $1 \%$ lidocain ) was performed. The first one was the most effective( lasted 4 months), each consecutive block was less effective. With the growing tolerancy on therapeutic effect on local anesthetic (lidocaine), cryoablation ( cryolesion) of great occipital nerve was offered to the patient.

METHODS : Unilateral greater occipital nerve block cryolesion was carried out under ultrasound scan control on the C2 level.Patient in prone position. After skin inflittration with $0.5 \mathrm{ml}$ lidocaine, Cryo-s probe $1.3 \mathrm{~mm}$ diameter, used in-plane position, the probe was inserted through $14 \mathrm{GA}$ catheter. Sensory stimulation of the GON was performed. Cryoablation was performed in 2 cycles of 2 -minutes cycle of freezing and after each 2 minutes time of defrost. In- plane probe position enable to visualize probe in ultrasound scan.

RESULTS: Five months from GON cryolesion procedure patient almost without migraine headaches. In the last two months the patient has reported 3-4 days with migraine headaches, NRS 2-3, reacting well with paracetamol or tolfenamic acid. Headaches do not intensify despite of occasional smoking and contraception (IUD).

CONCLUSION: For a few years I have been performing GON blocks to my migraine headaches patients. My experience shows that it is an effective method to relieve this kind of pain. However, the case of that patient indicates that with every consecutive block the tolerancy on local anesthetic may occur. With that special situation, GON cryoablation performing can be an effective method in migraine headache treatment. In medical literature hardly no information can be found related to cryoablation of GON in migraine headaches.

Surely this method is worth further investigations.
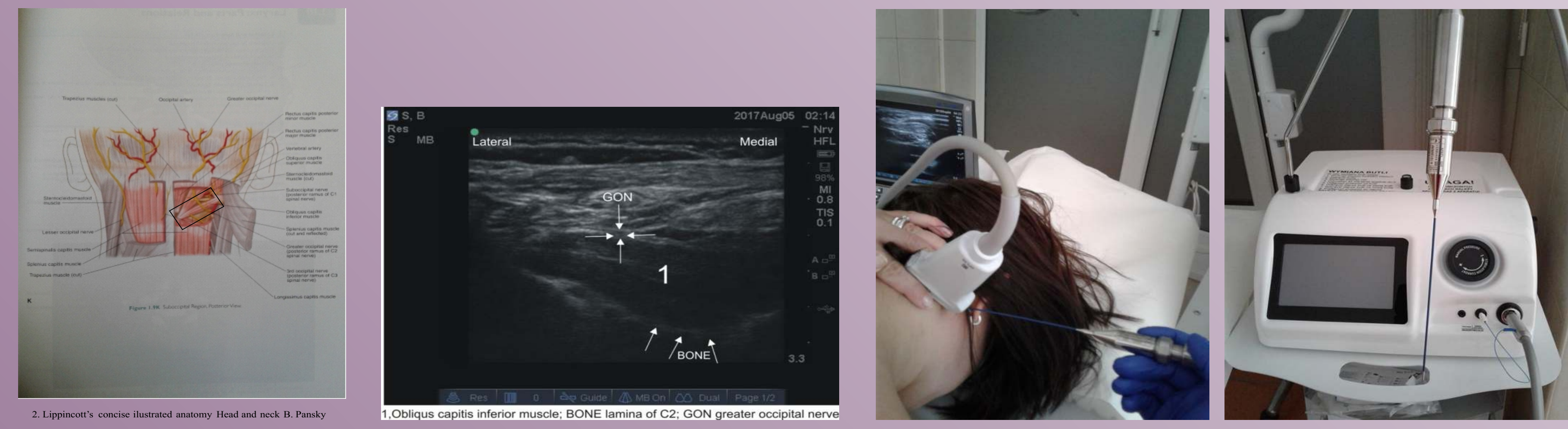